\title{
Expression of Galectin-3 in Normal and Malignant Thyroid Tissue by Quantitative PCR and Immunohistochemistry
}

Jonas Feilchenfeldt, Martin Tötsch, M.D., Sien-Yi Sheu, Ph.D., John Robert, M.D., Anastase Spiliopoulos, M.D., A. Frilling, M.D., Kurt W. Schmid, M.D., Christoph A. Meier, M.D. Endocrine Unit, Division of Endocrinology and Diabetes, Department of Medicine (JF, CAM), Division of Clinical Pathology, Department of Pathology (MT), and Clinic of Thoracic Surgery, Department of Surgery (JR, AS), University Hospital Geneva, Geneva, Switzerland; and Department of General Surgery and Transplantation (AF); Institute of Pathology (S-YS, KWS), University Hospital Essen, Essen, Germany

Galectin-3 has been extensively studied as an immunohistochemical marker of thyroid malignancy, and a high diagnostic accuracy has been reported even for difficult pathological diagnoses, such as minimal invasive follicular carcinoma. We consequently hypothesized that the quantitative analysis of galectin-3 mRNA rather than the more observerdependent immunohistological determination might enhance the diagnostic workup of ambiguous thyroid lesions. In the present study, we set out to validate this approach by analyzing concomitantly the expression and production of galectin-3 in benign and malignant thyroid tumors by means of quantitative PCR and immunohistochemistry. Twenty-eight benign and 31 malignant thyroid samples were quantified by real-time PCR for the mRNA levels of galectin-3 and thyroglobulin. Galectin-3 protein expression was examined by immunohistochemistry in 13 benign and 14 malignant thyroid samples. There was a significant increase in galectin-3 at both the mRNA (12/20) and protein levels in papillary cancer $(8 / 8)$, although the mRNA values overlapped partly with benign lesions. Surprisingly, only a focal and discrete galectin-3 immunoreactivity was seen in follicular cancer (1/5); no augmentation of the mRNA was found. The expression of the thyroid-specific gene thyroglobulin was highly variable in benign and malignant thyroid tissue. These results suggest that the quantitative

Copyright $\odot 2003$ by The United States and Canadian Academy of Pathology, Inc.

VOL. 16, NO. 11, P. 1117, 2003 Printed in the U.S.A.

Date of acceptance: August 15, 2003.

Supported by a research grant of the Swiss National Science Foundation and the Novartis Foundation to C.A.M.

Authors Feilchenfeldt and Tötsch contributed equally to this work

Address reprint requests to: Christoph A. Meier, M.D., Endocrine Unit,

University Hospital Geneva, 24, Rue Micheli-du-Crest, CH-1211 Geneva

14, Switzerland; fax: 41-22-372-9330; e-mail: christoph.meier@hcuge.ch.

DOI: 10.1097/01.MP.0000096047.99202.31 measurement of galactin-3 mRNA is unlikely to be clinically useful and underscore the need for searching for novel markers for thyroid malignancies.

KEY WORDS: Galectin-3, Real-time quantitative RTPCR, Thyroglobulin, Thyroid cancer.

Mod Pathol 2003;16(11):1117-1123

Fine-needle aspiration is the method of choice in evaluating clinically significant thyoid nodules. Although approximately $85 \%$ of the aspirated nodules are diagnosed as benign lesions, the remaining $15 \%$ are classified as microfollicular lesions, which means that no definite statement can be made as to their benign or malignant nature (1). Subsequently, 90-95\% of these patients currently undergo unnecessary thyroidectomy. Moreover, the diagnosis of follicular thyroid cancer, which relies on the criteria of vascular invasion and capsular infiltration, remains a challenge, particularly in the minimally invasive variant of follicular cancer, for which debates arise about what constitutes a true capsular infiltration (2). These problems have motivated the search for a suitable marker of malignancy that may improve the accuracy of the diagnosis and possibly reduce the number of unnecessary surgical interventions (3).

Two members of the lectin family, galectin-1 and galectin-3, have received particular attention. Lectins are carbohydrate-binding proteins that recognize specific oligosaccharide structures and ligands. Galectin-1 and galectin-3 belong to the family of galactoside-binding proteins, and they are polypeptides consisting of a short amino-terminal sequence, a repetitive collagen-like sequence that is rich in proline, glycine, and tyrosine and a $\mathrm{COOH}-$ terminal carbohydrate recognition domain (4). Galectins are localized on the cell surface and within 
the extracellular matrix, as well as in the cytoplasm and the nucleus of cells, and may serve as receptors for proteins of the extracellular matrix, such as laminin and fibronectin (5). Galectins are expressed in tissues such as colon, breast, and thyroid as well as in macrophages and activated endothelial cells, and they have been implicated in biological processes as diverse as cell growth, differentiation, apoptosis, inflammation, and angiogenesis (6-11).

Galectin-1 has been proposed to mediate cell-tocell and cell-to-matrix adhesion, to induce or to inhibit apoptosis; galectin-3 is known to mediate and inhibit cell adhesion and to participate in neutrophil and macrophage activation (5).

Several studies have analyzed galectin-1 and galectin-3 expression in benign and malignant thyroid tissue. Although galectin-1 mRNA levels have been described to be increased in 28/40 (70\%) papillary carcinomas, no change was seen in follicular carcinoma; moreover, galectin-1 protein levels were positive in all papillary carcinomas (12). In a second study, an increase in galectin-1 and galectin-3 protein expression was observed in 16/16 (100\%) papillary and 7/7 (100\%) follicular carcinomas; the normal or benign samples remained negative (13). A further study showed a positive galectin-3 immunoreactivity in 18/18 (100\%) papillary and 14/17 (82\%) follicular carcinomas, whereas only $3 / 29$ (10\%) follicular adenomas stained positively (14). Along the same lines, the most comprehensive study thus far showed immunohistochemical positivity for galectin-3 in 195/201 (97\%) papillary and 54/57 (95\%) follicular carcinomas; the analysis of galectin-3 in benign thyroid tissue was largely negative in $75 / 75(100 \%)$ normal control cases, 50/50 (100\%) hyperplastic lesions, and 121/ 125 (97\%) follicular adenomas (15). Subsequently, galectin-3 positivity could even be detected in $17 / 17(100 \%)$ minimal invasive follicular cancer carcinomas, supporting the view of galectin-3 as an early tumor marker of thyroid cancer (16).

However, in another study, galectin-3 positivity was found only in 4/9 (44\%) follicular carcinomas, whereas $27 / 28(96 \%)$ papillary carcinomas were positive (17). Recently, a quantitative study of galectin-3 mRNA showed no significant differences between follicular carcinomas and benign thyroid tissue (18). Intriguingly, another study indeed found galectin-3 immunoreactivity in 18/20 (90\%) follicular carcinomas but also found galectin-3 positivity in 14/17 (82\%) follicular adenomas (19).

In summary, although there is strong evidence for a potential role of galectin-3 as a marker for thyroid cancers, several studies have recently challenged the notion of galectin-3 as a tumor marker for follicular carcinoma (17-19). As immunohistochemical analysis is highly observer dependent, we hypothesized that the quantitative determination of galectin-3 mRNA levels by means of real-time quantitative PCR might be a more reliable and reproducible method that also could be applicable to fine-needle aspiration. Hence, we analyzed in the present study the expression levels of galectin-3 mRNA in normal and malignant thyroid tissue, comparing it with protein expression levels.

\section{MATERIALS AND METHODS}

\section{Patients and Samples}

Specimens of 20 papillary (including 1 follicular variant and 1 tall cell variant), 7 follicular (4 minimal invasive and 3 widely invasive, including 1 oxyphilic variant each), and 4 poorly differentiated thyroid cancers (1 anaplastic carcinoma, 3 insular carcinomas), 9 adenomas, 9 hyperplasias, and 10 normal thyroid glands were collected from 59 patients who were undergoing surgery at the University Hospital Hamburg (A.F.), Hamburg, Germany and University Hospital Essen (A.F., K.S.), Essen, Germany and University Hospital Geneva (J.R., A.S., M.T.), Geneva, Switzerland from January 1999 to December 2001. Information concerning age, sex, pTNM, and histologic subtype was retrieved by reviewing the pathology reports. After surgery, the material was snap-frozen in liquid nitrogen and stored at $-80^{\circ} \mathrm{C}$ for subsequent RNA extraction. The tissue block used for RNA extraction was verified histologically, and samples that did not contain $\geq 60 \%$ tumor cells were excluded from the study. Original paraffin blocks were accessible for 13 benign and 14 tumor samples (see Table 1) studied at two centers (Geneva and Essen).

\section{Immunohistochemistry}

Routinely processed formalin-fixed, paraffinembedded tissue sections were mounted onto coated slides and dried at $40^{\circ} \mathrm{C}$ overnight; then they were deparaffinized with xylene and rehydrated with graded ethanol concentrations. Endogenous peroxidase activity was blocked by incubation with $1.1 \% \mathrm{H}_{2} \mathrm{O}_{2}$ for 10 minutes. Nonspecific binding of the second antibody was avoided by preincubation with normal rabbit serum for 15 minutes. The sections were then incubated with the primary antibody to human galectin-3 (Clone: B2C10, diluted 1: 50; BD Biosciences-BD Pharmingen, San Diego, $\mathrm{CA})$; at $4^{\circ} \mathrm{C}$ overnight. The secondary antibody was detected with a standard ABC technique using 3,3'diaminobenzidine-tetrahydrochloride dihydrate (3,3'-diaminobenzidine) as chromogen.

Sections of normal colonic mucosa were used as external positive controls; omission of the primary antibody, as negative control. Sections were scanned at low power to identify areas that were 


\begin{tabular}{|c|c|c|c|}
\hline & & $\begin{array}{l}\text { Galectin-3 } \\
\text { Protein }\end{array}$ & $\begin{array}{c}\text { Galectin-3 } \\
\text { mRNA } \\
\text { (amol/ug RNA) }\end{array}$ \\
\hline & Variant & & \\
\hline \multicolumn{4}{|l|}{ Hyperplastic nodules } \\
\hline Case 1 & & 0 & 2.54 \\
\hline Case 2 & & 0 & 0.65 \\
\hline Case 3 & & 0 & 0.89 \\
\hline Case 4 & & 0 & 1.49 \\
\hline Case 5 & & 0 & 1.21 \\
\hline Case 6 & & $1^{a}$ & 1.87 \\
\hline Case 7 & & 0 & 0.23 \\
\hline Case 8 & & 0 & 1.03 \\
\hline \multicolumn{4}{|l|}{ Follicular adenomas } \\
\hline Case 1 & oxyph & 0 & 1.21 \\
\hline Case 2 & & 0 & 1.93 \\
\hline Case 3 & & 0 & 1.42 \\
\hline Case 4 & & 1 & 1.56 \\
\hline Case 5 & & 0 & 0.03 \\
\hline \multicolumn{4}{|l|}{ Follicular carcinomas } \\
\hline Minimal invasive Case 1 & & 0 & 0.581 \\
\hline Minimal invasive Case 2 & oxyph. & 0 & 0.31 \\
\hline Minimal invasive Case 3 & & 0 & 1.83 \\
\hline Widely invasive Case 4 & oxyph. & 1 & 0.93 \\
\hline Widely invasive Case 5 & & 0 & 0.31 \\
\hline \multicolumn{4}{|l|}{ Papillary carcinomas } \\
\hline Case 1 & & 3 & 18.91 \\
\hline Case 2 & & 2 & 1.87 \\
\hline Case 3 & & 3 & 20.15 \\
\hline Case 4 & & 3 & 5.77 \\
\hline Case 5 & & 3 & $b$ \\
\hline Case 6 & & 2 & 10.83 \\
\hline Case 7 & tall cell & 3 & $b$ \\
\hline Case 8 & foll. & 2 & 11.98 \\
\hline \multicolumn{4}{|l|}{ Anaplastic carcinoma } \\
\hline Case 1 & & 0 & 5.08 \\
\hline
\end{tabular}

Intensity score: $0=$ negative, $1=$ weak, $2=$ moderate, $3=$ strong staining.

${ }^{a}$ Pseudopapillary structure stained positive for galectin-3.

${ }^{b}$ Frozen tissue without tumor (excluded from RNA analysis).

evenly labeled, and an estimate of galectin-3positive cells was scored semiquantitatively, as follows: $0=$ all cells negative; $1=<30 \%$ positive cells; $2=30-60 \%$ positive cells; $3=>60 \%$ positive cells.

\section{RNA Extraction and cDNA Synthesis}

After the presence of tumor tissue was ascertained by histological examination of frozen sections from the tissue specimens, total RNA was extracted by using the TRIzol Reagent according to the manufacturer's instructions (LifeTechnologies Inc.) and quantified spectrophotometrically; its integrity was verified by gel electrophoresis. We reverse-transcribed $2.5 \mu \mathrm{g}$ of total RNA in a total volume of $32 \mu \mathrm{L}$ using $400 \mathrm{IU}$ of Moloney murine leukemia virus reverse transcriptase (LifeTechnologies Inc.), $0.3 \mathrm{U} / \mu \mathrm{L}$ of RNasin (Promega Corp., Madison, WI), $7.5 \mu \mathrm{M}$ oligo $(\mathrm{dN})_{6}, 1.2 \mathrm{~mm}$ dNTP, and $5 \times$ First strand buffer with $12 \mathrm{~mm}$ dithiothreitol and RNase-free $\mathrm{H}_{2} \mathrm{O}$.

\section{Primers and Plasmids}

Primers for galectin-3 and thyroglobulin were chosen with the assistance of the computer program Primer3 (20). The nucleotide sequences for the different primer pairs were as follows:

Galectin-3: sense 5' ATGCAAACAGAATTGCTTTAGATT 3', antisense 5' AGTTTGCTGATTTCATTGAGTTTT 3' (280 bp); thyroglobulin: sense 5' ATGCACTGGGGAACTCAAAG 3', antisense 5' TGAGGCTGAGAACACAATGG 3' (200 bp). The PCR products of galectin-3 and thyroglobulin (Fig. 1A) were cloned into the vector pCR3.1 (Invitrogen, Paisley, UK) and served as external standards.

\section{Quantitative Real-Time RT-PCR}

Copy numbers of galectin-3 mRNA and thyroglobulin mRNA were determined by quantitative real-time RT-PCR using a Lightcycler (Roche Diagnostics, Switzerland) with standard curves based on the serial dilution of the appropriate plasmid (2123). DNA Master SYBR Green I (Roche Molecular Biochemicals, Switzerland) was used for the two genes analyzed. Amplifications (10 $\mu \mathrm{L}$ reaction volume) were performed in glass capillary tubes; $2 \mu \mathrm{L}$ of cDNA, $1.2 \mu \mathrm{L}$ of magnesium chloride $(2.8 \mathrm{~mm})$, $4.8 \mu \mathrm{L}$ of sterile water, $1 \mu \mathrm{L}$ of SYBR Green I, and 1 $\mu \mathrm{L}$ of each primer $(0.5 \mu \mathrm{M})$ were used. The RT-PCR reactions were performed according to the Lightcycler standard protocol using the following annealing temperatures: galectin-3, $56^{\circ} \mathrm{C}$ and thyroglobulin, $57^{\circ} \mathrm{C}$. The specificity of the amplicon was confirmed by restriction digestion and sequencing. Cycle threshold values and calculated values were determined using the Lightcycler software (Version 5.32). Absolute mRNA concentrations were calculated from serially diluted (1:10) standard curves over a range of four to five orders and expressed as moles per microgram of RNA. Two separate runs were performed for each sample and the mean was calculated. To estimate the interrun variation, the values of the two independent runs of each gene of all samples were compared, and the correlation was nearly perfect (Fig. 1B-C). RNA samples without addition of reverse transcriptase served as negative controls.

\section{Statistical Analyses}

Differences between the different pathological categories were evaluated using the Mann-Whitney $U$ test, and correlations among parameters were assessed using the Spearman rank statistics with SYSTAT 10.01 (SPSS Inc, Chicago, IL). A $P$ value of $<.05$ was considered as significant. The median values are marked by a dashed line on the graphs. 


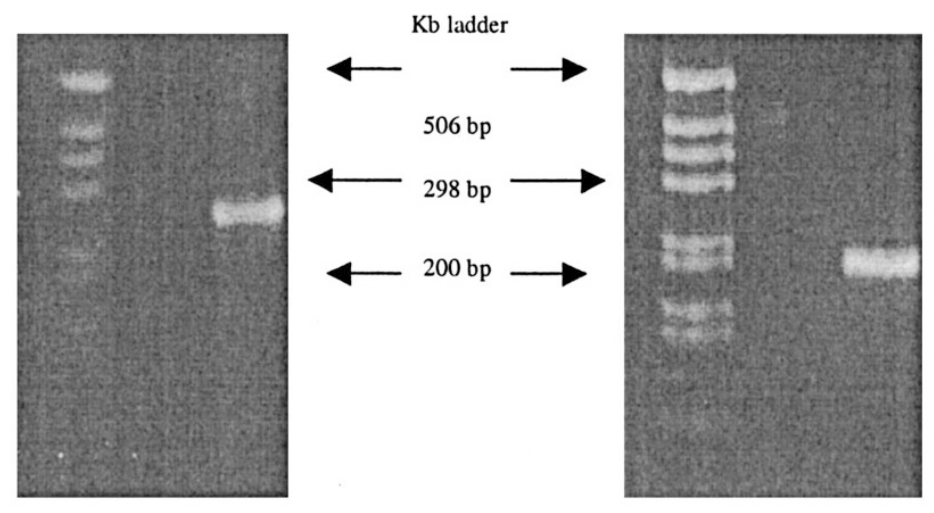

B

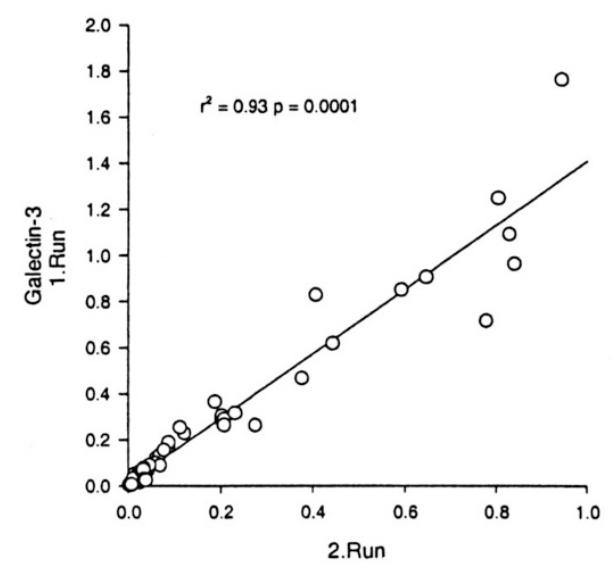

C

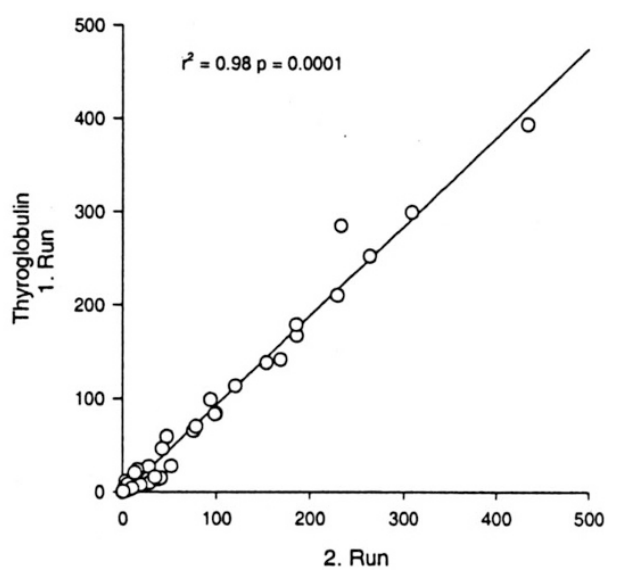

FIGURE 1. Analysis of galectin-3 and thyroglobulin mRNA by quantitative RT-PCR. A, agarose gel (2\%) stained with ethidium bromide of the PCR products of galectin-3 $(280 \mathrm{bp})$ and thyroglobulin $(200 \mathrm{bp})$. B, galectin-3: correlation between two independent Lightcycler runs of the same sample. C, thyroglobulin: correlation of two independent experiments (run) on the same sample.

\section{RESULTS}

Galectin-3 Expression in Benign Versus Papillary and Follicular Cancer

Galectin-3 expression varied between 0.03 and $2.75 \mathrm{amol} / \mu \mathrm{g}$ RNA in normal and benign thyroid tissue (normal: $n=10$, range 0.05-2.75; hyperplasia: $n=9$, range $0.23-2.14$; adenoma: $n=9$, range $0.03-2.14)$, with no significant changes among these groups.

A similar pattern was observed in follicular cancer ( $n=7$; range $0.3-2.1 \mathrm{amol} / \mu$ g RNA); thus, no difference was found between the benign tissue and the follicular cancer group (Fig. 2A). Neither extension of the tumor (minimal or widely invasive), nor oxyphilic differentiation had significant implications on Gal-3 expression (Table 1). In papillary cancer $(n=20)$, the values varied between 0.4 and $20.15 \mathrm{amol} / \mu \mathrm{g}$ of RNA. A subgroup of these patients' cases $(n=4)$, including the case of follic- ular variant, had values of $>10 \mathrm{amol} / \mu \mathrm{g}$ RNA. Though the overall increase observed in the papillary cancer group was 3.5 -fold $(P=.0001), 50 \%$ of the patients with papillary cancer had galectin-3 levels that overlapped with the levels found in benign lesions. Poorly differentiated cancers $(n=4$, including one anaplastic thyroid cancer) expressed galectin-3 at levels similar to those in papillary tumors.

\section{Thyroglobulin Expression in Benign Versus Papillary and Follicular Cancer}

Thyroglobulin expression showed a high variability ranging from $0.1-367 \mathrm{fmol} / \mu \mathrm{g}$ RNA in normal and benign thyroid tissue (normal: 0.6-367; hyperplasia: 0.1-2.7; adenoma: 0.3-228 fmol/ $\mu$ g RNA). No significant changes were observed compared with the papillary and follicular cancer group (Fig. 2B). Thyroglobulin expression was highly variable, also 

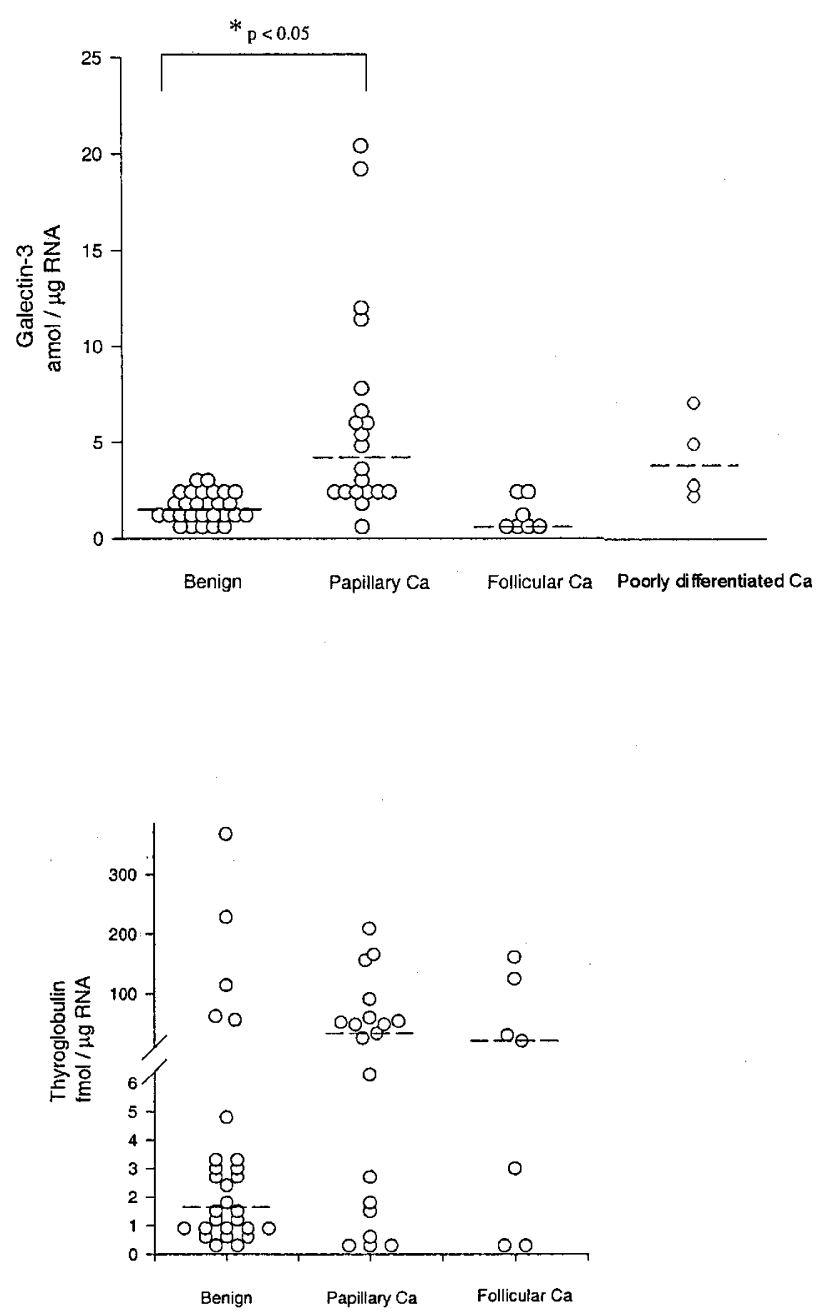

FIGURE 2. Expression of galectin-3 and thyroglobulin in benign and malignant tissue. A, absolute quantification of galectin-3 mRNA in 28 normal and benign thyroid samples, in 20 papillary cancer samples, and 7 follicular cancer samples. The group of poorly differentiated thyroid cancers includes one anaplastic carcinoma. Data are presented in attomoles per microgram of RNA as the mean of two independent runs. The dotted line represents the median value. B, absolute quantification of galectin-3 mRNA in 28 normal and benign thyroid samples, in 20 papillary cancer samples, and 7 follicular cancer samples. Data are presented in femtomoles per microgram of RNA as the mean of two independent runs. The dotted line represents the median value.

within thyroid cancer subtypes (papillary cancer: 0.05-209; follicular cancer: $0.21-161$; poorly differentiated cancer: $0-65 \mathrm{fmol} / \mu \mathrm{g}$ RNA).

\section{Characterization of Galectin-3 Protein Expression} by Immunohistochemistry in Benign and Malignant Lesions of the Thyroid

Seven of 8 (88\%) hyperplastic nodules were negative for galectin-3; in one sample, histologically benign pseudopapillary structures stained positive. Among five follicular adenomas, one sample was slightly positive for galectin-3 (20\%).

All eight papillary thyroid carcinomas stained positive for galectin-3, (100\%) whereas four $(80 \%)$ of five of the follicular carcinomas were completely negative for galectin-3, and one case was focally positive $(<5 \%$ and considered as negative; Table 1 ; Fig. 3). The single case of an anaplastic carcinoma examined was negative for galectin-3 immunostaining. To assess the correlation between mRNA and protein, the correlation coefficient was calculated and yielded a value of $r^{2}=0.65(P=.0001)$. Although all papillary carcinomas were positive for galectin-3 immunostaining, two corresponding mRNA values were not increased (cases 2 and 4).

\section{DISCUSSION}

Fine-needle aspiration and subsequent cytopathologic analysis are pivotal steps in the workup of a thyroid nodule, and certain pathologic situations exist in which the cytopathological report is equivocal ("microfollicular lesion"), and surgery is usually the only means by which to establish a definite diagnosis. Hence, reliable markers for thyroid cancers would be welcome to avoid unnecessary surgical interventions.

Members of the galactose-binding proteins have been extensively studied as potential markers of thyroid malignancy $(1,5,12,24-27)$. Recently, a large multicenter study compared galectin-3 in benign and malignant thyroid tissue and reported an excellent sensitivity (99\%) and specificity (98\%) for this marker (15). As immunohistochemical analysis is necessarily semiquantitative and strongly dependent on the protocol used and the experience of the observer, we wanted to assess whether galectin-3 mRNA levels would also correlate with the immunohistochemical diagnosis and whether a quantita-
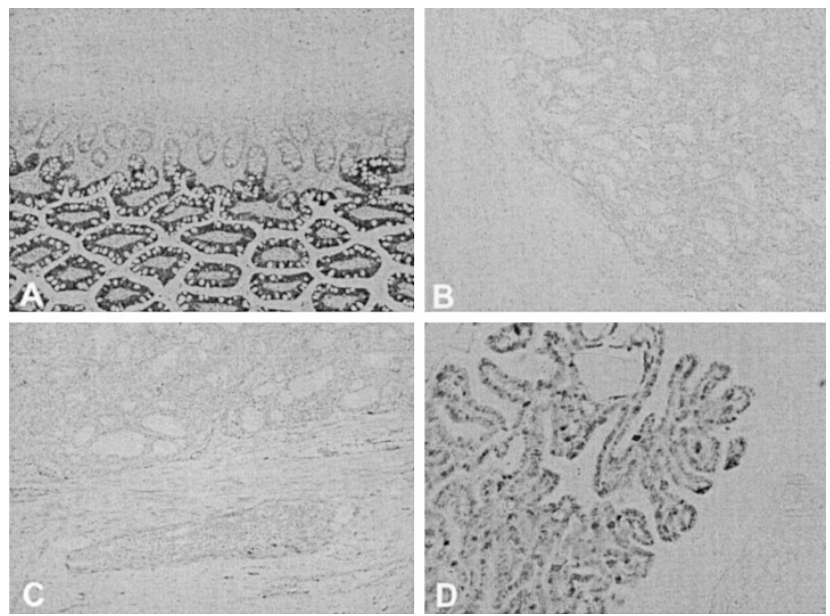

FIGURE 3. Analysis of galectin-3 by immunohistochemistry. A, positive external control by staining colonic mucosa $(10 \times)$. B, adenoma without positive staining $(10 \times)$. C, follicular carcinoma with vascular invasion. Vessels stain positive, tumor cells are negative $(20 \times)$. D, papillary carcinoma showing a positive reaction in all tumor cells $(20 \times)$. 
tive cutoff may be useful in differentiating benign from malignant thyroid tumors.

Real-time quantitative PCR has been established as a reliable and accurate quantitative method for the analysis of mRNA levels (23). So far, mainly thyroid-specific genes such as thyroglobulin or sodium-iodine symporter have been studied $(9,28)$. With the aim of performing quantitative PCR on fine-needle aspirations, a recently published work studied galectin-3 mRNA quantitatively in tissue specimens of different thyroid malignancies but did not observe an increase in galectin-3 in follicular cancer (18).

Regarding the literature, there are just a few studies investigating galectin-3 with material obtained by fine-needle aspiration. The methodological approach is quite variable; some apply immunocytochemistry (14, 15, 16, 29), some apply RT-PCR (30), and some apply both $(26,31)$. It has been shown that RT-PCR alone is not a reliable method for the evaluation of the galectin-3 expression, because macrophages and activated endothelial cells express galectin-3 (15). Furthermore, positive results in benign lesions such as colloid goiters or Hashimoto's thyroiditis are potential pitfalls when no cytological control is performed. However, most of the publications report detection of galectin-3 in nearly all cases of papillary and follicular carcinomas, regardless of which method was used. Just a few positive cases of follicular adenomas are described.

These findings cannot be supported by our study, in which we were working with a series of 59 thyroid tissue samples. In concordance with other studies, a significant increase in galectin-3 (at the protein level and, to a lesser extent, at the mRNA level) was observed in papillary cancers when compared with adenomas. However, in two cases of papillary cancer the galectin-3 mRNA was not increased, whereas immunohistochemistry was clearly positive. This observation indicates that the analysis at the protein level is more feasible than quantitative PCR, and we think that this may be due to degradation of mRNA.

In fact, all immunohistochemically analyzed papillary carcinomas stained positively for galectin-3; unfortunately, in a further eight papillary carcinomas with normal galectin-3 mRNA levels, no blocks were available for immunohistological analysis. We had just one case of the follicular variant in our study group; thus, our results concerning this interesting entity are not representative enough to be compared with those of other studies $(15,30)$.

In our series, both mRNA and protein levels of galectin-3 were not increased in follicular cancer. These results are in agreement with those of two previously published studies that did not find an increase in galectin-3 mRNA, much less galectin-3 positivity in immunohistochemical analysis (17, 18). However, the majority of the studies published so far describe an increased galectin-3 protein expression in thyroid carcinomas and, in particular, in follicular carcinomas. Whether the observed differences are related to tumor heterogeneity, pathological classification, or methodological problems remains unclear. In our study, no statistical significant differences could be observed in the four cases of minimally invasive and three cases of widely invasive follicular carcinomas. In contrast to other publications, our two cases of follicular carcinomas with oxyphilic differentiation showed no or minimal expression of galectin-3 by immunohistochemistry and quantitative PCR $(15,30)$.

The fact that in the case of anaplastic carcinoma, quantitative PCR revealed the presence of a considerable amount of galectin-3 mRNA, whereas immunohistochemistry was completely negative, may be explained by the fact that investigations were performed on different tissue blocks or by overfixation of the material. However, cases of negative immunohistochemistry results in anaplastic carcinoma have already been described (32).

As reported by other investigators, we observed a large variability in expression of thyroglobulin in all disease categories $(9,28)$. Although we observed an increased median value of thyroglobulin in thyroid cancers, this was not statistically significant.

In summary, we established and validated the quantitative analysis of galectin-3 mRNA levels by means of quantitative real-time PCR in benign and malignant thyroid tissue. We observed a significant increase in galectin-3 on mRNA and protein levels in papillary thyroid cancers. No follicular thyroid cancer was positive with regard to galectin-3 mRNA levels. Hence, galectin-3 expression or immunoreactivity do not appear to be useful tools in distinguishing adenomas from follicular cancers in cytological or histological specimens. However, it remains to be seen whether galectin-3 will prove useful in detecting the follicular variant of papillary cancers or a multifocal spread on histological material.

Acknowledgments: The authors are grateful for the assistance and helpful discussions of Dr. Karl Worm, Institute of Pathology, University Hospital Essen. The authors also wish to thank the technicians of the immunohistochemistry laboratory, Institute of Pathology, University Hospital Essen for establishing the galectin-3 protocol and performing the immunostaining. 


\section{REFERENCES}

1. Meier CA. Thyroid nodules: pathogenesis, diagnosis and treatment in thyroid nodules and thyroid cancer. Baillieres Clin Endocrinol Metab 2001;14:559-75.

2. Oertel YC, Oertel JE. Thyroid cytology and histology in thyroid nodules and cancer. Baillieres Clin Endocrinol Metab 2001;14:541-57.

3. Ringel MD. Molecular diagnostic tests in the diagnosis and management of thyroid carcinoma. Rev Endocr Metab Disord 2000;1:173-81.

4. Honjo $Y$, Nangia-Makker $M$, Inohara $H$, Raz A. Downregulation of galectin-3 suppresses tumorigenicity of human breast carcinoma cells. Clin Cancer Res 2001;7:661-8.

5. Perillo NL, Marcus ME, Baum LG. Galectins: versatile modulators of cell adhesion, cell proliferation, and cell death. J Mol Med 1998;76:402-12.

6. Schoeppner HL, Raz A, Ho SB, Bresalier RS. Expression of an endogenous galactose-binding lectin correlates with neoplastic progression in the colon. Cancer 1995;75:2818-26.

7. Liu FT, Hsu DK, Zuberi RI, Kuwabara I, Chi EY, Henderson WR. Expression and function of galectin-3, a betagalactoside-binding lectin, in human monocytes and macrophages. Am J Pathol 1995;147:1016-28.

8. Rosahl SK, Erpenbeck V, Vorkapic P, Samii M. Solitary follicular thyroid carcinoma of the skull base and its differentiation from ectopic adenoma-review, use of galectin-3 and report of a new case. Clin Neurol Neurosurg 2000;102:14955.

9. Ringel MD, Anderson J, Souza SL, Burch HB, Tambascia M, Shriver CD, et al. Expression of the sodium iodide symporter and thyroglobulin genes are reduced in papillary thyroid cancer. Mod Pathol 2001;14:289-96.

10. Barondes SH, Cooper DN, Gitt MA, Leffler H. Galectins. Structure and function of a large family of animal lectins. J Biol Chem 1994;269:20807-10.

11. Nangia-Makker M, Honjo Y, Sarvis R, Akahani S, Hogan V, Pienta Kjet, et al. Galectin-3 induces endothelial cell morphogenesis and angiogenesis. Am J Pathol 2000;156:899909.

12. Chiariotti L, Berlingieri MT, Battaglia C, Benvenuto G, Martelli ML, Salvatore P, et al. Expression of galectin-1 in normal human thyroid gland and in differentiated and poorly differentiated thyroid tumors. Int J Cancer 1995;64:171-5.

13. Xu XC, el-Naggar AK, Lotan R. Differential expression of galectin-1 and galectin-3 in thyroid tumors. Potential diagnostic implications. Am J Pathol 1995;147:815-22.

14. Orlandi F, Saggiorato E, Pivano G, Puligheddu B, Termine A, Cappia S, et al. Galectin-3 is a presurgical marker of human thyroid carcinoma. Cancer Res 1998;58:3015-20.

15. Bartolazzi A, Gasbarri A, Papotti M, Bussolati G, Lucante T, Khan A, et al. Application of an immunodiagnostic method for improving preoperative diagnosis of nodular thyroid lesions. Lancet 2001;357:1644-50.

16. Saggiorato E, Cappia S, De Giuli P, Mussa A, Pancani G, Caraci $\mathrm{P}$, et al. Galectin-3 as a presurgical immunocytodiagnostic marker of minimally invasive follicular thyroid carcinoma. J Clin Endocrinol Metab 2001;86:5152-8.

17. Niedobitek C, Niedobitek F, Lindenberg G, Bachler B, Neudeck H, Zuschneid W, et al. Expression of galectin-3 in thyroid gland and follicular cell tumors of the thyroid. A critical study of its possible role in preoperative differential diagnosis. Pathologe 2001;22:205-13.

18. Bernet VJ, Anderson J, Vaishnav Y, Solomon B, Adair CF, Saji $\mathrm{M}$, et al. Determination of galectin-3 messenger ribonucleic acid overexpression in papillary thyroid cancer by quantitative reverse transcription-polymerase chain reaction. J Clin Endocrinol Metab 2002;87:4792-6.

19. Martins L, Matuso SE, Ebina KN, Kulcsar MAV, Friguglietti CU, Kimura ET. Galectin-3 messenger ribonucleic acid and protein are expressed in benign thyroid tumors. J Clin Endocrinol Metab 2002;87:4806-10.

20. Rozen S, Skaletsky HJ. www-genome.wi.mit.edu/genome_software/other/primer3.html.

21. Shappell SB, Gupta RA, Manning S, Whitehead R, Boeglin WE, Schneider C, et al. 15S-Hydroxyeicosatetraenoic acid activates peroxisome proliferator-activated receptor gamma and inhibits proliferation in PC3 prostate carcinoma cells. Cancer Res 2001;61:497-503.

22. Bieche I, Laurendeau I, Tozlu S, Olivi M, Vidaud D, Lidereau $\mathrm{R}$, et al. Quantitation of MYC gene expression in sporadic breast tumors with a real-time reverse transcription-PCR assay. Cancer Res 1999;59:2759-65.

23. Kreuzer KA, Lass U, Bohn A, Landt O, Schmidt CA. LightCycler technology for the quantitation of bcr/abl fusion transcripts. Cancer Res 1999;59:3171-4.

24. Cvejic D, Savin S, Paunovic I, Tatic S, Havelka M, Sinadinovic J. Immunohistochemical localization of galectin-3 in malignant and benign human thyroid tissue. Anticancer Res 1998; 18:2637-41.

25. Fernandez PL, Merino MJ, Gomez M, Campo E, Medina T, Castronovo V, et al. Galectin-3 and laminin expression in neoplastic and non-neoplastic thyroid tissue. J Pathol 1997; 181:80-6.

26. Gasbarri A, Martegani MP, Del P, Lucante T, Natali PG, Bartolazzi A. Galectin-3 and CD44v6 isoforms in the preoperative evaluation of thyroid nodules. J Clin Oncol 1999;17: 3494-502.

27. Kawachi K, Matsushita Y, Yonezawa S, Nakano S, Shirao K, Natsugoe S, et al. Galectin-3 expression in various thyroid neoplasms and its possible role in metastasis formation. Hum Pathol 2000;31:428-33.

28. Lazar V, Bidart JM, Caillou B, Mahe C, Lacroix L, Filetti S, et al. Expression of the $\mathrm{Na}+/ \mathrm{I}-$ symporter gene in human thyroid tumors: a comparison study with other thyroid-specific genes. J Clin Endocrinol Metab 1999;84:3228-34.

29. Capotti M, Volante M, Maggiorato E, Deandreis D, Veltri A, Orlandi F. Role of galectin-3 immunodetection in the cytological diagnosis of thyroid cystic papillary carcinoma. Eur J Endocrinol 2002;147:515-21.

30. Niedziela M, Maceluch J, Korman E. Galectin-3 is not an universal marker of malignancy in thyroid nodular disease in children and adolescents. J Clin Endocrinol Metab 2002;87: 4411-5.

31. Aratake Y, Umeki K, Kiyoyama K, Hinoura Y, Sato S, Ohno A, et al. Diagnostic utility of galectin-3 and CD26/DPPIV as preoperative diagnostic markers for thyroid nodules. Diagn Cytopathol 2002;26:366-72.

32. Beesley MF, McLaren KM. Cytokeratin 19 and galectin-3 immunohistochemistry in the differential diagnosis of solitary thyroid nodules. Histopathology 2002;41:236-43. 